\title{
Video feedback in tertiary music performance classes
}

\author{
Carol Johnson, Alana Blackburn \\ University of Melbourne, University of New England
}

\begin{abstract}
Video feedback can be an important and key mechanism for supporting online student learning in higher education. In the context of online music teaching, video feedback provides a necessary audio and visual element to support music students' learning of music performance practice. A predecessor to a larger study in video feedback, this pilot study sought to explore instructor perceptions of the use of video feedback in music performance teaching classes. Using self-study methodology, findings suggest that video feedback can effectively complement individualised online music teaching within an undergraduate performance class and a Master of Music Performance Teaching group music class, provide supportive scaffolding for self-regulated learning, and offer students opportunities to create meaningful student-instructor connections and community. Strategies for effective implementation by way of self-regulation and communication are also addressed.
\end{abstract}

Keywords: video feedback; music performance teaching; online learning; self-regulated learning; community

\section{Introduction}

Teaching music online in higher education is an art in and of itself; creativity in the development of online music class content and structure provide opportunities to explore new approaches to teaching and learning. As music instructors seek to ensure equitable teaching for both on-campus and online music performance classes, attention to the class format (i.e., asynchronous, synchronous, and synchronous dual mode teaching) need to be considered. Given the intricate, and acute detail of musical instrument mechanisms, finger-, hand-, and overall body-movements, as well as high-fidelity audio quality requirements when teaching music, the identification of online teaching approaches that feature audio, video and graphic representation are necessary. Together, what is being taught about music performance practise (i.e., content), and how students are given opportunity to engage in and with the content and instructor (i.e., type of technology used) are intricately linked for student learning success.

Video feedback is a learning support that allows students to receive instructor feedback through a combination of audio, video and graphic means. Using basic video recording software, an external microphone, and a web camera, music instructors can record a short three to five-minute video response to music students that goes beyond the limits of text-based feedback. Enabling instructors to address students' individualised performance abilities and skills, the of an instructor providing responses to students' assessments through a video feedback mechanism can also be an effective teaching approach for teaching music online. While video feedback use is a familiar tool during students' practise times (Boucher, Creech \& Dubé, 2019), research on instructor's use of video feedback as a feedback tool for student assessments is limited. Therefore, the purpose of this article is to examine the opportunities and challenges of video feedback for online music teaching as identified through selfstudy (Bullough \& Pinnegar, 2001) and highlight strategies for effective implementation.

\section{Background}

As we examine the use of video feedback in online music performance teaching, we need to consider how instructor feedback has been used in the past to support student learning. Building upon research for effective instructor feedback, the impact of the online environment must also be identified to ensure that the technology does not negatively impact how the student retrieves and perceives the feedback given. Therefore, this section addresses the impact of supporting students with feedback that not only delivers the feedback as a formative learning mechanism but is presented to the online student as an approach that is in alignment with music performance learning and online learning. 


\section{Importance of Feedback Using Text in Music Performance Learning}

Assessment is essential to student learning and feedback is a crucial part of the assessment process. Although there are general principles that guide effective feedback, the delivery method could be more effective depending on the task and the format of the course itself. Gibbs and Simpson (2004) provide six general guidelines for using feedback to positively enhance student performance:

- $\quad$ Feedback should be frequent and detailed

- $\quad$ Feedback should address students' individual learning tasks and learning objectives

- $\quad$ Feedback needs to be provided in a timely manner to ensure feedback is relatable and usable for future learning tasks

- $\quad$ Feedback should be clearly aligned to the assessment and appropriate rubric criteria

- $\quad$ Feedback should be given in a manner that supports students' understanding and relationship to the learning task; and

- $\quad$ Feedback is actionable and supports accountability for further learning outcomes.

Feedback quality ensures that students know what they should be learning and to what extent they are meeting the specified course learning outcomes. Traditionally, text-based feedback has been used as a common mechanism for formative and summative assessment in higher education. In music performance, text-based feedback is often used to provide feedback on summative performance assessment while formative verbal feedback is given by the teacher (or lecturer) in an individual lesson or class. Over time, research has shown that text-based feedback has become less-personalised due to increasing class sizes and other teacher-expectations.

Decreased personalisation has led into a growing amount of dissatisfaction between students and teachers (Nicol, 2010). It is also notable that written feedback itself is often not being read or taken up by students. That is, there is an increasing lack of students engaging with feedback (Glover \& Brown, 2015). Challenges pertaining to written feedback include: vague comments; illegible if handwritten; inconsistent in quality; and often "focus on positive and encouraging comments at the expense of clear advice on how to improve the quality of subsequent work" (McCarthy, 2015, p. 155). While written feedback can address the earlier guidelines outlined by Gibbs and Simpson (2004), research suggests that written feedback is not always effective in supporting student engagement for further learning.

In music performance, and applied music studies, we find written feedback used as a common feedback mechanism during summative assessment processes such as student recital and technical examinations or large music projects. In these assessment formats, written feedback has been identified as an effective way to address the technical and expressive (i.e., subjective) aspects of music performance (DeLuca \& Bolden, 2014). Yet, during the teaching period, much of the face-to-face music performance teaching happens in one-to-one connections and through modeling in smaller formative assessments leading up to the large recital examinations or projects. That is, formative feedback is often provided face-to-face between teacher and one or more students through individual instruction or in a class (Weyde et al., 2007).

Such face-to-face instruction gives students access to immediate synchronous visual and audio feedback which the student can immediately apply into their performance learning and limits the delivery of a final written report which subsumes an "authoritarian style" (Blom \& Poole, 2004, p. 112) and single observation. Given the importance of music as 'music making' (i.e., in constant development), feedback mechanisms should also provide students with opportunities to consider broader time periods, allow for interactive and conservational exchanges, and take place within a timely manner. Video feedback is a tool that can address each of these necessary components for online music performance feedback.

\section{Exploring Video Feedback for Music Performance}

Music performance students are more familiar with a traditional, synchronous learning environment, and often receive immediate formative feedback during lessons and classes (Blackburn, 2017). However, in online music performance studies, text-based feedback can be more prevalent due to the asynchronous nature of some of the necessary individual performance tasks and assessments. Further, given the niche nature of online music classes, academic teaching workshops in higher education often focus on approaches to feedback which require limited technological skills and can be generalised across the academy. 
However, video feedback is a powerful technology tool that can provide meaningful engagement with creative arts students. A study by McCarthy (2015) set out to examine multiple forms of summative feedback mechanisms. This comparative study on audio, video and written feedback in a media arts course at the University of South Australia showed that written feedback (i.e., with rubric) was the least preferred method with preference from $22 \%$ of the students and video feedback had a preference of $66 \%$ with the students. Findings from the study also suggest that written feedback is less engaging and more impersonal than video and audio feedback. The overall limitations of written feedback were the lack of visual or aural elements as it can be conceived as less substantial and detailed as more could be said within a few minutes than typing or writing text. Video feedback was found to be a more active and lively method of providing feedback. In a cross comparison, the use of video and audio allowed for instructors to provide students with engaging and personal feedback, highlighting "Vocal tone and emphasis can improve understanding of feedback" (McCarthy, 2015, p. 163). Overall, video, and aural feedback mechanisms helped the online students feel connected with their marker/teacher viewing them as a person instead of an institution.

\section{Creating Connection in Video Feedback}

Music is in itself a sonic art form. Having feedback that links into the discipline itself (i.e., through the use of sound), is not only reasonable, but upholds the authentic aspect of teaching and learning music. Blom and Poole (2004) suggest video can be used in peer or self-review in music learning. Further, video feedback encourages learning, knowing how to learn and knowing what is to be learned, which together can develop further skills that can be used beyond performance. Therefore, it is suggested that video, and video feedback, play an important part in music performance assessment, and music learning activities, overall.

Video feedback can support the online music student to make connections to their learning. For example, we know that relatedness, autonomy, and competence (i.e., Self-Determination Theory) are known to support increased intrinsic motivation (Ryan \& Deci, 2000). Exploring these components of self-determination theory, it is further understood that as students feel included and cared for, the concept of relatedness can be achieved. This second component of autonomy can be addressed as students are able to have their personal learning goals and current achievements acknowledged by the teacher during the video feedback. Finally, the understanding of overall student competence and the level of achievement attained is the main outcome of the video feedback itself. Therefore, when video feedback is crafted to address each of these three psychological needs, or portion thereof, students can achieve increased intrinsic motivation.

Given the importance of intrinsic motivation in learning, it is identified that students need to feel aspects of relatedness, autonomy and competence in feedback. Therefore, this study sought to explore the opportunities and challenges of using video feedback in music performance classes.

\section{Methodology}

Discussions and collaborations in the area of online music pedagogy (Johnson, 2017) brought the two researchers together. Through the exploration of online learning activities and assessments, the exploration of approaches for using video feedback transpired. Across a two-month period, the two researchers discussed their assessment feedback approaches for their online music performance classes--one taught a Bachelor of Music Performance class, and the other taught a Master of Music Performance Teaching class. As part of her supplement for assessment feedback, one researcher had been providing her students with video feedback since 2019. The other instructor had yet to use teacher video feedback but was keen to see how it could be used to support feedback clarity. Given that the online students were already submitting their various music performances via video, using a similar communication method of response was reasonable and the video format supported clarity of message. It was established that both instructors would include four video performance activities within their respective 11-week and 12-week classes. During the classes, the instructors journaled and responded to questions regarding their online video feedback implementation, feedback responses and technology use.

Self-study research methodology was chosen due to its focus on both development of professional skill and personal understanding of self-as-practitioner (Samaras \& Freese, 2006). Common to self-study is the central aspect of personal inquiry and the context of the audience involved in the learning. That is, "self-study is distinct from practitioner research because the focus on the ' $I$ ' and with audience is critical in shaping and refining one's work" (Lunenburg \& Samaras, 2011, p. 842). Each researcher-as-instructor kept a diary that centred of what Schon (1987) describes as reflection-in-action (e.g., what overall topics were highlighted in the video responses 
and what visual demonstrations were offered) and reflection-on-action (e.g., how students responded to the instructor's videos, considerations to improve video feedback techniques).

To further substantiate the quality and transparency of the research, the researchers-as-instructors chose to use the Bullough and Pinnegar's (2001) Guidelines for Quality in Self-Study Research which is supported by the American Educational Researcher Association (AERA). To ensure these guidelines were followed, each instructor took time to interrogate their ideas and conceptions of video feedback through multiple questions and viewpoints, explored tensions through collaborative and individual examinations, and examined personal perspectives, all in a manner that was thoughtfully framed, structured and organised to look for new perspectives of thought.

\section{Music Performance Video Feedback Activity}

Instructor A chose to have four graded video activities across the semester. Each student had to upload three 'practise videos' during the trimester (teaching period) so their performance preparation could be informally 'assessed' and formative feedback could be provided during their learning. The final assessment, a public performance, was also recorded and uploaded as a summative assessment. Instructor video feedback was provided for each these four video assessments.

Instructor B had two informal video activities and two formal graded video activities. Instructor B's two informal video activities served as trial opportunities for students to learn how to successfully complete their recording and submission in a low-stakes learning scenario. This helped support students to feel comfortable with the technology in a non-graded assessment, while being able to receive important feedback in the first weeks of classes.

\section{Discussion and Results}

Both researchers-as-instructors had previous familiarity with creating videos and, more specifically, videos for music teaching. This provided the instructors with little challenge for creating and implementing video technology into their assessment feedback. Each video feedback for the student was approximately three to five minutes in length and was uploaded to the student grades area of the Learning Management System, along with their regular text- or rubric-based feedback tool used.

The pilot study identified that as music instructors we can embrace video feedback in online music teaching similarly to how we engage with our face-to-face teaching. However, the similarities focused on basic human expressions and behaviours. Differences found when creating video feedback focused on individualised strategies for implementing effective video feedback that enabled instructors to consider interaction of video as a real and embodied communication presence. This overarching approach for creating 'presence' when recording video feedback was realised in how instructors engaged within a camera viewing space, focusing on making it considered connection through the technology as vehicle, and expecting students to take up the practical feedback given in the video.

There were three themes identified from the study: 1) video feedback was an effective compliment for meaningful learning (i.e., it can effectively complement individualised music teaching within both group music classes); 2) video feedback provided supportive scaffolding for self-regulated learning, and 3) video feedback can support meaningful student-instructor connections and community.

\section{Effective Compliment: It's the Content not Delivery Mode}

Of particular note, was that students often remarked on the depth of content, and its relevance to their practise rather than the experience of the video itself. For example, Instructor A remarked, 'They [students] focused more on the content of the feedback rather than the delivery of the feedback.' This means that students found they connected more to the feedback because the instructor and the video (i.e., communication tool), did not have a perceived barrier; the instructor talked to the camera as if the student was in the room in a one-to-one learning exchange. 'Group teaching didn't permit detailed learning exchanges for each student, but video feedback gave opportunity for personalised learning' (Instructor B). While listening to student video assessments, the instructors made small written notes with reminders of content detail to highlight during the video. Individualised and meaningful learning was noted by students in their response comments to instructors' video feedback. Further, students shared their video feedback with each other to gain new skills, or to listen to 
the instructor describe a particular performance technique from a different perspective. Overall, student remarks highlighted the helpful, assistive, and personalised nature of the video content.

\title{
Scaffolding for Self-Regulated Learning
}

Given the body of research that identifies the importance of self-regulation for online learners (Allen \& Seaman, 2013), and, in particular, for musicians as learners (McPherson, in press; Zimmerman, 2000), the connection of self-regulation needs to be explicitly actioned within an online music class. For example, students began to evidence further autonomy and competence in their learning. This also resulted in students evidencing increased self-regulated learning.

I realised late into the semester, that the key questions I asked students to answer in their videos focused on elements of autonomy and overall self-regulation in their learning. As students created their videos and chose to respond to three out of six questions, my feedback response was able to address specific scaffolding concepts for self-regulation that may not have been fully explored by the student. (Instructor B)

\section{Meaningful Student-Instructor Connections and Community}

Video feedback allowed instructors to use facial expression, body gesture and voice intonation to emphasise certain aspects (and reframe negative feedback), to enhance encouragement. It allowed for the contextualization of open-ended questions better and provided a better opportunity to discuss more abstract features such as dynamics (e.g., clap/tap), pitch (e.g., singing), bowing (e.g., act out and demonstrate), and characterise (e.g., change voice/face). Instructor B highlighted connections of trust made through video feedback:

Through the use a video, and in particular students hearing my voice and seeing my image, a higher level of trust was exchanged. This was noted as students continued the conversations from previous weeks across their video submissions.

Overall, the feedback was used to provide students with reminders of how they are in alignment with the class learning and texts (where appropriate), as well as highlight opportunities for exploring further resources mentioned in class or elsewhere. These exchanges were found valuable to students as the feedback allowed for deeper and different learning approaches than what was possible in the group class, and provided students with evidenced, real-world application of their performance and practise concepts. Instructor A remarked:

\begin{abstract}
As my class has a mixture of instruments, as a teacher providing feedback you have to draw from your teaching 'toolkit' to be able to adapt the feedback to students of different instruments and backgrounds. Video feedback provides more flexibility for teachers to do this. Because this is a fully online class which doesn't have (or not regular) synchronous online classroom meeting, this is an opportunity for students to connect and meet the teacher (even if asynchronous).
\end{abstract}

Overall, the results of the instructor journaling identified that the experience of using video feedback to support assessment feedback was a supportive tool for both the instructors and the students. As instructors, we were able to provide audio and visual feedback on music performance that allowed for detailed finger movements, body posture, embouchure technique and overall performance techniques and skills. Students found the feedback useless for as a comparison marker to their own technique, overall clarity of communication, and encouraged the student to review their own video for self-reflection.

\section{Strategies for Effective Implementation}

From the study, it is suggested that there are two key strategies that can support effective implementation of video feedback: Development of self-regulation within video feedback and specific communication strategies for effective use of video technology.

\section{Development of Self-Regulation Within Video Feedback}

The online music class can be used as an effective mechanism to model and support self-regulation skills. Specifically, it can be crafted to reinforce the three main components of self-regulated learning as summarised by McPherson (in press). These components are: Forethought Phase (i.e., goal setting; self-efficacy, etc.), 
Performance Phase (i.e., self-instruction; help-seeking, etc.) and Self-Reflection Phase (i.e., self-evaluation, etc.).

From our findings, it is suggested that effective video feedback implementation addresses elements of selfregulated learning. That is, each element of self-regulated learning can be scaffolded and integrated into video feedback on an individualised basis. For example, as experienced by Instructor B, students were given key questions to think about, and respond to, as part of a learning task or activity. This task required students to create a short three-minute video of a current and then take an additional minute to address two or three questions from a list of focused self-regulation questions. Students became more connected and intrinsically motivated in their learning as they chose which questions to include in their videos and what songs to showcase their performance levels. As students talked about how they watched and listened to their own videos, they began to identify some of their own performance errors, and inefficiencies in practise that helped them move through their learning through the phases of self-regulation.

In practise, it was found that the identification of specific questions that students could address in their video performances helped them to consider self-assessment of their self-regulation. For example, Instructor B asked her students to include a one-minute response in each performance video to three short questions chosen from a selection of six self-regulation questions. In essence, each of the six possible questions were prompts that helped students to identify where they are at with their individual learning, and in turn guided them through a surface examination of self-regulation skills. Examples of these questions that can help guided such self-assessment include:

- What is your biggest challenge this week?

- What strategies are you using to improve your playing?

- What music have you been listening to this week?

- What are you doing well this week?

\section{Communication Strategies for Effective Use of Video Feedback Technology}

Overall, the study identified common communication strategies that were used by both instructors to help develop 'presence; through the medium of video to the students. Specific strategies are outlined (see Table 1). In general, the most compelling connections were made with profession and positive communication behaviours. These communicative connection strategies included: creating a positive atmosphere through smiling, humour, encouragement, providing positive reinforcement and beginning each video feedback with highlights of the student's more successful aspects of performance.

Table 1: Communication strategies used in video feedback for music teaching

\begin{tabular}{ll}
\hline $\begin{array}{l}\text { Sound Recording } \\
\text { and Clarity }\end{array}$ & $\begin{array}{l}\text { Choose a microphone that best supports the instrument, or voice, being taught; } \\
\text { Higher-end USB mics have gain adjustment. }\end{array}$ \\
\hline $\begin{array}{l}\text { Camera and } \\
\text { Position }\end{array}$ & $\begin{array}{l}\text { Use of two cameras (i.e., one for up-close captures and one for full body position, or } \\
\text { instrument viewing) that are easily movable; Use of a tripod may be best for camera } \\
\text { positioning. }\end{array}$ \\
\hline Eye Contact & $\begin{array}{l}\text { Pro-actively look into the camera when talking about individualised student } \\
\text { comments; }\end{array}$ \\
\hline Language & $\begin{array}{l}\text { Use conversational language that would be common in a face-to-face studio teaching } \\
\text { time; aim to converse like you and the student are in the same 'place'; Greet Students } \\
\text { by name in the video; Respond to their particular questions asked; Providing } \\
\text { constructive criticism which focuses on the issue rather than the person } \\
\text { (technique, musical suggestions). }\end{array}$ \\
\hline Professionalism & $\begin{array}{l}\text { Dress appropriately and film in my office to keep the professional student/teacher } \\
\text { association }\end{array}$ \\
\hline $\begin{array}{l}\text { Recording } \\
\text { Techniques }\end{array}$ & $\begin{array}{l}\text { Take time to explore different camera angles, object placement within a video frame, } \\
\text { and effective audio instrument recording techniques to support communication. }\end{array}$ \\
\hline
\end{tabular}




\section{Challenges}

Providing video feedback in this way posed very few challenges due to the instructors having a high level of technical skill. Between both instructors they had over 20-years experience of teaching music online. One potential challenge could be a slow internet speed to upload videos and larger file sizes. This was not an issue for either instructor as they had access to high-speed internet and Learning Management Systems that can support larger files. Although video feedback proved to be an efficient way to communicate to students, the time taken to upload video files could prove problematic with very large classes.

As we look to the future research, further exploration into overall student perceptions of the use of video feedback by online music instructors, and the extent to which video feedback can support student learning outcomes are warranted. Given the limited research in online music assessment activities overall, it can be suggested that exploration into case studies as well as supportive online music assessment frameworks would also be found beneficial.

\section{Conclusions}

From the above pilot study, it is reasonable to suggest that video feedback can be a supportive mechanism for online music students. The technology itself affords the use of audio, video and graphic communication that is exemplifies an equitable and distributed learning experience in the online environment. Video feedback provides students with an engaging learning experience that relates more closely to their experiences with a more traditional face-to-face environment performance classes normally take. Instructors are able to visually and audibly explain through gesture particular techniques, signals and expressive forms of movement which provide deeper and more meaningful learning experiences for students without the worry of misunderstanding. Video feedback also provided the opportunity for instructors to contribute timely, detailed feedback that was individualised and supported each student in their learning. Further, the results highlight three outcomes of video feedback use in online music classes: 1) video feedback as effective compliment for meaningful music performance learning; 2) video feedback as a supportive scaffolding for self-regulated learning, and 3) video feedback as meaningful in the development of student-instructor connections and community. These three outcomes support effective musician performance training; the ability to construct meaning, self-reflection and self-regulation, and connections with community are important features of the professional musician's skillset. A scenario in online teaching that can support these outcomes shows best practice, and effective use of online teaching and learning.

Together, with the adoption of strategies that seek to develop self-regulation skills and the use of effective video communication strategies, video feedback can be an interactive and engaging teaching tool for the online music performance classroom.

\section{References}

Allen, I. E., \& Seaman, J. (2013). Changing course: Ten years of tracking online education in the United States. Sloan Consortium. http://files.eric.ed.gov/fulltext/ED541571.pdf

Blackburn, A. (2017). Performing online: Approaches to teaching performance studies in higher education within a fully online environment. Australian Journal of Music Education 51(1). pp. 63-72.

Blom, D. \& Poole, K. (2004). Peer assessment of tertiary music performance: opportunities for understanding performance assessment and performing through experience and self-reflection. British Journal of Music Education, 21(1), 111-125. https://doi.org/10.1017/S0265051703005539

Bullough, R. V., \& Pinnegar, S. (2001). Guidelines for Quality in Autobiographical Forms of Self-Study Research. Educational Researcher, 30(3), 13-21. https://doi.org/10.3102/0013189X030003013.

Duncan, N. (2007). 'Feed-forward': Improving students' use of tutors' comments. Assessment \& Evaluation in Higher Education, 32(3), 271-283. https://doi.org/10.1080/02602930600896498

Gibbs, G. \& Simpson, C. (2004). Conditions under which assessment supports learning. Learning and Teaching in Higher Education, 1(1), 3-31.

Glover, C., \& Brown, E. (2006). Written Feedback for Students: too much, too detailed or too incomprehensible to be effective?, Bioscience Education, 7(1), 1-16. https://doi.org/10.3108/beej.2006.07000004

Johnson, C. (2017). Teaching music online: Changing pedagogical approach when moving to the online environment. London Review of Education, 15(3), 439-456. https://doi.org/10.18546/LRE.15.3.08 
Lunenburg, M., \& Samaras, A. (2011). Developing a pedagogy for teaching self-study research: Lessons learned across the Atlantic. Teaching and Teacher Education 27(5), 841-850. https://doi.org/10.1016/j.tate.2011.01.008

McCarthy, J. (2015). Evaluating written, audio and video feedback in higher education summative assessment tasks. Issues in Educational Research, 25(2), 153-169.

McPherson, G. (in press). Self-regulated learning music microanalysis. In G. McPherson (Ed.) Oxford Handbook of Music Performance. Oxford Press.

Nicol, D. (2010). From monologue to dialogue: improving written feedback processes in mass higher education, Assessment \& Evaluation in Higher Education, 35(5), 501-517. https://doi.org/10.1080/02602931003786559

Ryan, R. M., \& Deci, E. L. (2000). Self-determination theory and the facilitation of intrinsic motivation, social development, and well-being. American Psychologist, 55(1), 68+ https://doi.org/10.1037/0003-066X.55.1.68

Samaras, A. P., \& Freese, A. R. (2006). Self-study of teaching practices. Peter Lang Primer.

Weyde, T., Ng, K., Neubarth, K., Larkin, O., Koerselman, T. and Ong, B. (2007). A Systemic Approach to Music Performance Learning with Multimodal Technology. Paper presented at the Support E-Learning Conference, 2007, Quebec City, Canada.

Zimmerman, B. J. (2000). Attaining self-regulation: A social cognitive perspective. In M. Boekaerts, P. R. Pintrich \& M. Zeidner (Eds.), Handbook of Self-Regulation (pp. 13-40). San Diego, CA: Academic Press. https://doi.org/10.1016/B978-012109890-2/50031-7

Johnson, C. \& Blackburn, A. (2021). Video feedback in tertiary music performance Classes. In Gregory, S., Warburton, S., \& Schier, M. (Eds.), Back to the Future - ASCILITE '21. Proceedings ASCILITE 2021 in Armidale (pp. 103-110). https://doi.org/10.14742/ascilite2021.0114

Note: All published papers are refereed, having undergone a double-blind peer-review process.

The author(s) assign a Creative Commons by attribution licence enabling others to distribute, remix, tweak, and build upon their work, even commercially, as long as credit is given to the author(s) for the original creation.

(C) Johnson, C., \& Blackburn, A. 2021 